\title{
PREVALENCE OF STRESS AND ITS ASSOCIATED FACTORS AMONG MEDICAL STUDENTS IN SABAH, MALAYSIA BORNEO
}

\author{
Aldrin Musiun ${ }^{1}$, Khamisah Awang Lukman, ${ }^{1,2}$ Mohammad Saffree Jeffree ${ }^{1}$, Fredie Robinson ${ }^{1}$, Mohd Rohaizat \\ Hassan ${ }^{3}$, Hasanain Faisal Ghazi ${ }^{4}$, Al-abed Ali Ahmed Al-abed ${ }^{5}$,Naing Oo Tha ${ }^{1}$, Swe ${ }^{1}$ and Shamsul Bahari \\ Shamsudin ${ }^{1}$ \\ ${ }^{1}$ Department of Community \& Family Medicine, Faculty of Medicine \& Health Sciences, Universiti Malaysia \\ Sabah, Kota Kinabalu, Sabah, Malaysia \\ ${ }^{2}$ Centre for Occupational Safety \& Health, Universiti Malaysia Sabah, Kota Kinabalu, Sabah, Malaysia \\ ${ }^{3}$ Department of Community Health, Faculty of Medicine, University Kebangsaan Malaysia, Kuala Lumpur, \\ Malaysia \\ ${ }^{4}$ Community Medicine Unit, International Medical School, Management and Science University, Selangor, \\ Malaysia. \\ ${ }^{5}$ Department of Community Medicine, Faculty of Medicine, Lincoln University College, Petaling Jaya, Selangor, \\ Malaysia
}

Corresponding Author: Khamisah Awang Lukman

Email: khamisah@ums.edu.my

\begin{abstract}
Stress is accepted as the accumulation of unpleasant state of physical, mental and emotion on a person. Medical education has been known as one of the most stressful academic curriculum. Hence, medical students may subjected to multiple psychological changes and challenges throughout the years of medical education. The aim of this study was to determine the prevalence of stress and its associated factors among medical students. This cross sectional study was conducted from April to May 2018 in medical school in Sabah. It involved 396 medical students through universal sampling. Selfadministered questionnaires were used as an instrument for data collection. The questionnaires included were Sociodemographic Questionnaire, Depression, Anxiety and Stress Scales 21 (DASS-21) and Medical Student Stressors Questionnaire (MSSQ). Bivariate analysis (Chi Square test, Fisher's Exact Test, Independent $T$ test and Man-Whitney U test) were used to analyse the association. The response rate was $90.2 \%$. The prevalence of stress among medical students were $33.3 \%$. Significant associated factors include financial support inadequacy $(p=0.010)$ and all categories of medical student stressors. The mean score of the academic related stressors was found to be at $2.117( \pm 0.758)$ which was the highest mean score among medical student stressors assessed by MSSQ. The result of this study can be used as a basis for implementation of preventive measures such as provision of comprehensive, integrated and responsive mental health care services in university-based settings.
\end{abstract}

KEYWORDS: Stress, stressor, medical students, medical education, mental health, DASS , MSSQ

\section{INTRODUCTION}

Stress is generally defined as an accumulation of unpleasant state of physical, mental and emotion on a person. Stress happens when there are interactions between individuals and their surrounding that are perceived as exceeding their coping ability and negatively affecting their wellbeing. Alternatively, stress is referring to nonspecific body response mechanism towards demands or strains made on itself or environment ${ }^{1}$. A stressor is generally understood as a situation that potentially triggers a stress response in human being. The Diagnostic and Statistical Manual of Mental Disorders IV defines a psychosocial stressor as any life event or life change that may be associated temporally with the onset, occurrence or exacerbation of a mental disorder ${ }^{2}$. Stress may eventually lead to impaired judgement, reduced concentration, reduced self-esteem, increased anxiety and increased depression. Exposure to chronic stress may lead to both physical and mental illnesses ${ }^{3}$. Based on Malaysia National Health and Morbidity Survey 2015, the prevalence of mental health problem among adult aged 16 years and above in Malaysia was $29.2 \%$.

Medical education aims to equip and prepare future medical doctors with adequate medical knowledge and competency to contribute to the development of medicine field as well as for the wellbeing of the society. Unfortunately, some aspects of medical education learning environment lead to negative consequence on medical student's psychosocial health. Medical education is considered to be very stressful due to its structure with a high proportion up to $40 \%$ affected with psychological distress ${ }^{5}$. 
Most of the time, medical education is perceived as being stressful due to the nature of the course, the workload and the demand. The stress caused by the medical education learning process is characterized by many psychological changes in medical students ${ }^{6}$. The ongoing stress in undergraduate medical course may eventually continue later in internship, postgraduate study, later in clinical practical life and it may reach burnout level ${ }^{7}$. Medical students encounter multiple anxieties in transformation from being insecure student to young knowledgeable physician and subjected to many psychological changes ${ }^{6}$. Systemic review of studies reporting on stress among Arab medical students showed high prevalence of psychological morbidity and its various stages of their training up to $67.0 \%^{8}$. High levels of stress may lead to mental distress and has a negative impact on cognitive functioning and learning 9 . A negative effect of stress may eventually result in feelings of distress, rejection, anger and depression which subsequently lead to health problems ${ }^{10}$. Stress in undergraduates are influencing mental health as well as honesty, academic performance and use of alcohol and others drugs ${ }^{11}$. The excessive amount of stress in medical training may lead to negative consequences such as diminished attention and concentration, increased incidence of errors, negligence, absenteeism, self-medication, and cheating during examinations ${ }^{12}$.

It is crucial to create and maintain a well-balanced medical education learning environment for optimal learning experience among undergraduate medical students. A systemic review of literatures of stress among medical students in Malaysia revealed the prevalence of stress varies from $14-56 \%{ }^{13}$. Other researchers have found prevalence of stress among medical students was $31.2 \%$ in three British universities, $41.9 \%$ in Malaysia medical school and $61.4 \%$ in Thai medical school ${ }^{14}$. Transition from preclinical to clinical training has been identified as one of the important stressor ${ }^{15}$. A systemic review of 40 studies revealed that the overall psychosocial distress, prevalence of depression and anxiety in medical students are higher than non-medical students or age matched peers from general population ${ }^{16}$. Among the students in institutes of higher education, medical students appear to have more emotional challenges, physical and psychosocial hazards, and mood disorders as they progress and think of their future and professional goals ${ }^{12}$. Stress among medical students to a certain extent may negatively affect their physical and mental health as well their academic performance and personal development. Several studies revealed that persistent stressful conditions were associated with mental and physical health problems in medical students at various stages of their training ${ }^{3}$. Chronic exposure to persistent stressful conditions is also associated with inhibition of students' academic achievement and personal growth development ${ }^{6}$. There is inadequate updated or recent published evidence on stress issue among medical students. The last two researches were done by the external researchers in 2008-2009 ${ }^{17-18}$. However, for that particular study, medical students were only the subset of the total studied population. There was no previous study done to investigate the prevalence of stress and its associated factors involving the entire medical students.

What is the prevalence of stress among medical students and its associated factors? It is an important public health concern due to its potential to cause wide range of social and economic complications and negative consequence on physical health. This study was an effort to gain an additional epidemiology information on prevalence of stress and the associated stressors among medical student. The result of this study is expected to provide the details and updated extent of stress problem among medical students. It is hoped that it would be beneficial and can be utilized by the academic or faculty administrators as a basis for planning, implementation or improvement of preventive measures in order to help medical students to cope with the ongoing stress throughout the years of medical education. It can also be used as a reference for future researchers who interested to explore on the stress issue among medical students.

\section{MATERIALS \& METHODS}

This study was a cross sectional study to measure and describe the prevalence of stress and it associated factors among medical students in medical school in Sabah. This study was conducted from April to May 2018. The study population consists of 439 first to fifth academic year medical students. All medical students from first year to fifth year whom had completed at least one semester of academic study period were included in this study. Medical students with psychiatric illness, with chronic illness, on psychotropic drugs, or physically disabled were excluded from this study. Universal sampling technique was used in this study and single proportion formula was applied to estimate the population proportion. In this study, the anticipated population proportion (p) was based according to the previous study ${ }^{17}$. Self-administered questionnaires and informed consent forms were distributed to medical students during face to face sessions in a lecture hall according to the year of study. The purpose of the study was well explained to the respondents prior to the test. Informed consent was taken from all participants before participating in this study. Participation in this 
study was voluntary. Medical students were given about 15 to 30 minutes to complete and finish the questionnaire. They were required to submit the questionnaire at the end of the session (on the same day).

The self-administered questionnaire was divided into 3 parts. The first part asked information about socio-demographic factors such as age, Gender, Ethnicity, Year of academic study, family residence, family income, Religion and marital status. The second part included potential specific personal factors such as practice of religion, student accommodation, living with, type of financial support, financial adequacy, part time work, close friend and love relationship. The second part of the questionnaire was the application of the Depression, Anxiety, Stress Scales questionnaire to measure the prevalence of stress among medical students $^{21}$. Stress in this study was defined and measured by the score of DASS-21 questionnaire. DASS-21 is a short version of DASS questionnaire and included three self-administered scales designed to measure the negative emotional states of depression, anxiety and stress. Based on the final score of DASS-21, the level of stress among the respondents was defined as: Level 0-14 Normal, Level 15-18 Mild stress, Level 19-25 Moderate stress, Level 26-33 Severe stress and Level 34+ Extremely severe stress. The third part of the questionnaire was the application of Medical Student Stressors Questionnaire to determine the stressors among medical students ${ }^{17-20}$. There were 40 items in MSSQ represented the potential source of stress among medical students. The stressors were grouped into 6 main domains namely: Academic related stressor, Inter/Intrapersonal Related Stressor, Teaching and Learning Related Stressor, Social Related Stressor, Drive \& Desire Related Stressor, and Group Activities Related Stressor. Based on the final score of MSSQ, level of stress for each medical student stressors were finally determined as: Mild Stressor: Indicates that it did not causes any stress. Even if it did, it just causes mild stress, Moderate Stressor: Indicates that it did reasonably causes stress and can be managed well, High Stressor: Indicates that it did causes a lot of stress. It leads to emotional disturbance and daily activities are mildly compromised, Severe Stressor: Indicates that it did causes severe stress. It leads to severe emotional disturbance and daily activities are severely compromised. Data were analysed using SPSS version 24.0.

Descriptive statistic was applied to describe, organize and summarize the prevalence of stress, sociodemographic factors, potential specific personal factors and medical student stressors. Chi Square test and Fisher's Exact test were used to test the association between two categorical data. Independent $\mathrm{T}$ test and Man Whitney $\mathrm{U}$ test were used to test the association between numerical and categorical data. Research ethics approval was approved by the Ethical Committee on 23 February 2018 with the approval code of JKEtika 1/18 (4).

All respondents were informed that their information will be kept as confidential information. Due to confidential and ethical issue, the identity of students with severe stress were not revealed. However the overall result of this research was presented to the faculty and practical modification was recommended to tackle this issue.

\section{RESULTS}

The prevalence of stress among medical students was recorded at $33.3 \%$. Out of 396 medical students, $59(14.9 \%)$ experienced mild stress, $9.8 \%$ experienced moderate stress, $6.8 \%$ experienced severe stress and $1.8 \%$ experienced extremely severe stress respectively. The mean (SD) stress score in this study was $12.275(8.2)$.

Table 1: Medical student stressors score

\begin{tabular}{lccc}
\hline \multicolumn{1}{c}{ Variables } & Mean (S.D) & Min & Max \\
\hline Academic related stressors & $2.117(0.758)$ & 0.15 & 4.00 \\
Intra and interpersonal related stressors & $1.500(0.895)$ & 0.00 & 4.00 \\
Teaching and learning related stressors & $1.517(0.782)$ & 0.00 & 4.00 \\
Social related stressors & $1.495(0.740)$ & 0.00 & 3.50 \\
Drive and desire related stressors & $1.110(0.936)$ & 0.00 & 4.00 \\
Group activities related stressors & $1.679(0.827)$ & 0.00 & 4.00 \\
\hline
\end{tabular}

S.D: Standard deviation

Out of 439 medical students, 396 of them responded and returned the questionnaire. As such 396 medical students were included in this study giving a response rate of $90.2 \%$. The age of the medical students ranged from 18 to 27 years old and median age of the respondents was 22.0 years old. Out of 
the 396 medical students, 292 (73.7\%) were female. The number of medical student's participation based on year of academic study were approximately equal with the highest response 82 $(20.7 \%)$ were from third year medical students. Most of the medical students, $182(46 \%)$ had monthly family income more than RM 4000 monthly and 284 $(71.7 \%)$ of stated that their family's residence was in urban area. Majority of the medical students 393 $(99.2 \%)$ were single.

Table 2: The association between sociodemographic factors and stress status-part $A(n=396)$

\begin{tabular}{|c|c|c|c|c|}
\hline \multirow[b]{2}{*}{ Variables } & \multicolumn{2}{|c|}{ Stress } & \multicolumn{2}{|c|}{ Value } \\
\hline & $\begin{array}{c}\text { Yes } \\
\text { n (\%) }\end{array}$ & $\begin{array}{c}\text { No } \\
\text { n (\%) }\end{array}$ & $X^{2}(d f)$ & $P$ value \\
\hline Gender & & & $0.260(1)$ & 0.872 \\
\hline Male & $34(32.7)$ & $70(67.3)$ & & \\
\hline Female & $98(33.6)$ & $194(66.4)$ & & \\
\hline Ethnicity & & & $7.686(2)$ & 0.021 \\
\hline Bumiputra & $82(37.3)$ & $138(62.7)$ & & \\
\hline Chinese & $20(21.5)$ & $73(78.5)$ & & \\
\hline Indian \& Punjabi & $30(36.1)$ & $53(63.9)$ & & \\
\hline Indigenous or native group & & & $3.457(1)$ & 0.063 \\
\hline Bumiputra & $82(37.3)$ & $138(62.7)$ & & \\
\hline Non Bumiputra & $50(28.4)$ & $126(71.6)$ & & \\
\hline Year of academic study & & & $5.882(4)$ & 0.208 \\
\hline First & $28(34.6)$ & $53(65.4)$ & & \\
\hline Second & $25(32.5)$ & $52(67.5)$ & & \\
\hline Third & $32(39.0)$ & $50(61.0)$ & & \\
\hline Forth & $29(37.7)$ & $48(62.3)$ & & \\
\hline Fifth & $18(22.8)$ & $61(77.2)$ & & \\
\hline Phase of academic study & & & $0.05(1)$ & 0.942 \\
\hline Pre-clinical & $53(33.5)$ & $105(66.5)$ & & \\
\hline Clinical & $79(33.2)$ & $159(66.8)$ & & \\
\hline Family Residence & & & $0.622(1)$ & 0.430 \\
\hline Urban & $98(34.5)$ & $186(65.5)$ & & \\
\hline Rural & $64(30.4)$ & $78(69.6)$ & & \\
\hline Family Income & & & $1.150(2)$ & 0.563 \\
\hline$<2000$ & $22(28.2)$ & $56(71.8)$ & & \\
\hline $2000-4000$ & $47(34.6)$ & $89(65.4)$ & & \\
\hline$>4000$ & $63(34.6)$ & $119(65.4)$ & & \\
\hline Religion & & & $7.666(4)$ & 0.105 \\
\hline Muslim & $56(37.1)$ & $95(62.9)$ & & \\
\hline Buddhist & $16(20.3)$ & $63(79.7)$ & & \\
\hline Hindu & $26(36.1)$ & 46 (63.9) & & \\
\hline Christian & $31(36.5)$ & $54(63.5)$ & & \\
\hline Other & $3(33.3)$ & $6(66.7)$ & & \\
\hline Marital Status & & & & *0.554 \\
\hline Yes & $0(0.0)$ & $3(100)$ & & \\
\hline No & $132(33.6)$ & $231(66.4)$ & & \\
\hline
\end{tabular}

Statistical test: Chi square test, *Fisher's Exact Test, Significant at $p<0.05, d f$ : degree of freedom

Majority 271 (68.4\%) of the medical students graded their religious practice as always. $375(94.7 \%)$ medical students stayed in the hostel provided by institution and most of them $363(91.7 \%)$ stayed with their friend as a roommate or housemate. Out of 396 medical students, $328(82.8 \%)$ of the medical students were financially assisted by scholarship or study loan. About $133(33.6 \%)$ medical students personally felt that their financial support was generally inadequate. Small proportion of the medical students $8(2 \%)$ of them had part time job. Most of medical students $365(92.2 \%)$ claimed to have a close friend and 126 (31.8\%) were currently engage in a love relationship. 
Table 3: The association between potential specific personal factors and stress status $(n=396)$

\begin{tabular}{|c|c|c|c|c|}
\hline \multirow[t]{2}{*}{ Variables } & \multicolumn{2}{|c|}{ Stress } & \multicolumn{2}{|c|}{ Value } \\
\hline & $\begin{array}{l}\text { Yes } \\
\text { n (\%) }\end{array}$ & $\begin{array}{c}\text { No } \\
n(\%)\end{array}$ & $X^{2}(d f)$ & $P$ value \\
\hline Practice of religion & & & $0.23(1)$ & 0.878 \\
\hline Always & $91(33.6)$ & $180(66.4)$ & & \\
\hline Sometimes & $41(32.8)$ & $84(67.2)$ & & \\
\hline $\begin{array}{l}\text { Student accommodation } \\
\text { Hostel }\end{array}$ & $123(32.8)$ & $252(67.2)$ & $0.905(1)$ & 0.341 \\
\hline Home & $9(42.9)$ & $12(57.1)$ & & \\
\hline Living with & & & $1.678(2)$ & 0.432 \\
\hline Friend & $118(32.5)$ & $245(67.5)$ & & \\
\hline Alone & $6(37.5)$ & $10(62.5)$ & & \\
\hline Family & $8(47.1)$ & $9(52.9)$ & & \\
\hline Type of financial support & & & $1.500(1)$ & 0.221 \\
\hline Scholarship/Study loan & $105(32.0)$ & $223(68.0)$ & & \\
\hline Family & $27(39.7)$ & $41(60.3)$ & & \\
\hline Financial support adequacy & & & $10.959(1)$ & 0.010 \\
\hline Inadequate & $59(44.4)$ & $74(55.6)$ & & \\
\hline Adequate & $73(27.8)$ & $190(72.2)$ & & \\
\hline Part time working & & & & ${ }^{*} 0.724$ \\
\hline Yes & $2(25.0)$ & $6(75.0)$ & & \\
\hline No & $130(33.5)$ & $258(66.5)$ & & \\
\hline Close friend & & & $3.430(1)$ & 0.064 \\
\hline Yes & $117(32.1)$ & $248(67.9)$ & & \\
\hline No & $15(48.4)$ & $16(51.6)$ & & \\
\hline Love relationship & & & $3.352(1)$ & 0.067 \\
\hline Yes & $34(27.0)$ & $92(73.0)$ & & \\
\hline No & $98(36.3)$ & $172(63.7)$ & & \\
\hline
\end{tabular}

Statistical test: Chi square test, "Fisher's Exact Test , Significant at $p<0.05$, df: degree of freedom

The details of medical student stressors score were elaborated in Table 1. There was no statistical significant difference in mean of age between stressed and non-stressed of medical students. $(P=0.278, \quad Z=-1.085)$. Other socio demographic factors did not show significant association with development of stress among medical students. Table 2 showed the detailed of the association between sociodemographic factors and stress status among medical students. Chi square revealed a statistical significant association between financial support inadequacy and stress among medical students. $(P=0.010, P O R=2.075)$. Other potential specific personal factors did not show significant association with development of stress among medical students. Table 3 showed the detailed of the association between Potential Specific Personal Factors and stress status among medical students. Chi square test revealed statistical significant association between all medical student stressors and stress among medical student. $(P=<0.001)$. The details of relationship between medical student stressor and stress among medical student was summarized in Table 4. There were statistical significant difference in mean score of all categories medical student stressors between stressed and non-stressed medical students. The detail of relationship between the mean of medical student stressors score and stress among medical students was summarized in Table 5. 
Table 4: The association between medical student stressors \& stress status $(n=396)$

\begin{tabular}{|c|c|c|c|c|}
\hline \multirow[t]{2}{*}{ Variables } & \multicolumn{2}{|c|}{ Stress } & \multicolumn{2}{|c|}{ Value } \\
\hline & $\begin{array}{l}\text { Yes } \\
\mathrm{n}(\%)\end{array}$ & $\begin{array}{c}\text { No } \\
n(\%)\end{array}$ & $X^{2}(d f)$ & $P$ value \\
\hline Academic related stressors & & & $65.859(3)$ & $<0.001$ \\
\hline Mild & $0(0.0)$ & $26(100)$ & & \\
\hline Moderate & $34(19.4)$ & $141(80.6)$ & & \\
\hline High & $65(43.6)$ & $84(56.4)$ & & \\
\hline Severe & $33(71.7)$ & $13(28.3)$ & & \\
\hline Intra and interpersonal related stressors & & & $39.546(3)$ & $<0.001$ \\
\hline Mild & $24(16.4)$ & $122(83.6)$ & & \\
\hline Moderate & $56(38.9)$ & $88(61.1)$ & & \\
\hline High & $36(42.9)$ & $48(57.1)$ & & \\
\hline Severe & $16(72.7)$ & $6(27.3)$ & & \\
\hline $\begin{array}{l}\text { Teaching and learning related stressors } \\
\text { Mild }\end{array}$ & $19(16.7)$ & $95(83.3)$ & $43.409(3)$ & $<0.001$ \\
\hline Moderate & $58(30.7)$ & $131(69.3)$ & & \\
\hline High & $46(57.5)$ & $34(42.5)$ & & \\
\hline Severe & $9(69.2)$ & $4(30.8)$ & & \\
\hline $\begin{array}{l}\text { Social related stressors } \\
\text { Mild }\end{array}$ & $23(18.9)$ & $99(81.1)$ & $33.875(3)$ & $<0.001$ \\
\hline Moderate & $62(32.5)$ & $129(67.5)$ & & \\
\hline High & $40(54.1)$ & $34(45.9)$ & & \\
\hline Severe & $7(77.8)$ & $2(22.2)$ & & \\
\hline $\begin{array}{l}\text { Drive and desire related stressors } \\
\text { Mild }\end{array}$ & $57(25.2)$ & $169(74.8)$ & 27.057 (3) & $<0.001$ \\
\hline Moderate & $41(35.7)$ & $74(64.3)$ & & \\
\hline High & $24(61.5)$ & $15(38.5)$ & & \\
\hline Severe & $10(62.5)$ & $6(37.5)$ & & \\
\hline $\begin{array}{l}\text { Group activities related stressors } \\
\text { Mild }\end{array}$ & $11(10.9)$ & $90(89.1)$ & $73.224(3)$ & $<0.001$ \\
\hline Moderate & $51(27.7)$ & $133(72.3)$ & & \\
\hline High & $51(58.6)$ & $36(41.4)$ & & \\
\hline Severe & $19(79.2)$ & $5(20.8)$ & & \\
\hline
\end{tabular}

Statistical test: Chi square test, Significant at $p<0.05$, df: degree of freedom

\section{DISCUSSION}

The prevalence of stress among medical students was found to be at $33.3 \%$. Previous studies on Malaysian medical student stress level reported the prevalence ranging from $14.3 \%$ to $56.0 \%{ }^{13}$. Another previous research have found prevalence of stress among medical students was $31.2 \%$ in 3 British universities, $41.9 \%$ in Malaysia medical school and $61.4 \%$ in Thai medical school ${ }^{14}$. Comparison of finding needs to be done carefully due to the difference in study population, sample size, study design and tool of data collection. The mean score of stress among medical students was recorded at $12.275 \pm 8.185$ and graded as normal level of stress score following DASS-21 scoring definition. There was a significant difference in mean score of stress between stressed and non-stressed medical students $(p<0.001)$ suggestive of stressed medical students may experience significantly higher level of stress compare to non-stressed medical students.

An association test reported no statistically significant difference in mean of age between stressed and non-stressed of medical students. Therefore, age might not be the associated risk factor for development of stress among medical student. This finding was inconsistent compare to previous finding which identified younger age as significant for higher stress ${ }^{18}$. Gender was found to 
be statistically significant with stress among medical students ${ }^{19}$. Female medical student showed slightly higher prevalence (33.6\%) of stress compare to male $(32.7 \%)$ in which consistent with several previous findings ${ }^{22}$. However, association test did not suggest gender as the associated risk factor for development of stress among medical student. Prevalence of stress among medical students was recorded highest in third year $(39.0 \%)$ and was lowest in fifth year $(22.8 \%)$ of academic study. This finding was consistent with previous study ${ }^{17-20}$. The highest prevalence of stress in third year of academic study might be contributed by the transition and adaptation period from preclinical year to clinical year. Whereas, the lowest prevalence of stress in fifth year might be contributed by the developed skills to manage and cope with stress in medical learning environment ${ }^{17 .}$ ${ }^{20}$. Prevalence of stress based on phase of academic study among medical student showed approximately equal proportion with $33.5 \%$ in preclinical and $33.2 \%$ in clinical phase of academic study. Further association tests revealed year and phase of academic study were insignificant risk factors for development of stress among medical students. Those with family's residence located in rural area experienced slightly higher prevalence of stress $(37.3 \%)$ compared to those with family's residence located in urban area $(34.5 \%)$. This might be contributed by the transition and adaptive period from rural home town environment to urban learning environment.

Table 5: The association of mean score of medical student stressors between stressed and non-stressed medical students $(n=396)$

\begin{tabular}{|c|c|c|c|c|}
\hline Variables & $\begin{array}{c}\text { Yes } \\
\text { Mean Rank or } \\
\text { Mean (S.D) }\end{array}$ & $\begin{array}{c}\text { No } \\
\text { Mean Rank or } \\
\text { Mean (S.D) }\end{array}$ & $\begin{array}{c}Z \\
\text { or } \\
T \text { (df) }\end{array}$ & P Value \\
\hline ARS & $\begin{array}{c}2.5699 \\
(0.6674)\end{array}$ & $\begin{array}{c}1.8910 \\
(0.6972)\end{array}$ & $\begin{array}{l}9.264 \\
(394)\end{array}$ & ${ }^{*}<0.001$ \\
\hline IIRS & 253.76 & 170.87 & -6.802 & $<0.001$ \\
\hline TLRS & 253.76 & 170.87 & -6.805 & $<0.001$ \\
\hline SRS & 248.85 & 173.33 & -6.205 & $<0.001$ \\
\hline DDRS & 240.45 & 177.52 & -5.199 & $<0.001$ \\
\hline GARS & 266.88 & 164.31 & -8.442 & $<0.001$ \\
\hline
\end{tabular}

Statistical test: *Independent $T$ test, Man-Whitney U test, Significant at $p<0.05$, S.D; Standard deviation, df; Degree of freedom

As for the family income, medical students with family income less than RM 2000 per months experience lower prevalence of stress $(28.2 \%)$ compare to those with family income from RM 20004000 (34.6\%) and family income more than RM 4000 per month (34.6\%). None of these factors identified to have statistically significant association with development of stress among medical students. As for marital status, all married student did not reported stress compared to single medical students (33.6\%). Previous study stated married students were significantly less stressed compare to single status ${ }^{24}$. However, association test did not reveal any significant association. The potential specific personal factors related to stress among medical student had also been investigated in this study. Medical students who were staying in the hostel experienced lower prevalence of stress (32.8\%) compared to those who were staying at home (42.9\%). This finding might be contributed by extra supportive, encouraging, ideal learning environment in the hostel compared to non-hostel environment. Medical student who were staying with friend experienced lower $(32.5 \%)$ prevalence of stress compared to those who were staying alone $(37.5 \%)$ and with family members $(47.1 \%)$. However, none of these factors identified to have statistically significant association with development of stress.

Medical students who were financially depending on their families experienced higher level of stress (39.7\%) compared to those who additionally assisted by scholarship (32.0\%). This finding might be contributed by family financial difficulties and high financial burden as the cost of studying in medicine is relatively high. However, further association test did not suggest financial support as a significant risk factor for development of stress. About one third of the medical students personally felt that their financial support was generally inadequate to cover 
the expenses during their study. This study has confirmed the significant association between financial support inadequacies with stress among medical students. Those who experienced inadequate financial support reported higher prevalence of stress $(44.4 \%)$ compared to those with adequate financial support (27.8\%). This finding was consistent with the finding of previous similar studies $^{5,14}$. Only small proportion $(2.0 \%)$ of medical students had part time job. In general, those with part time job are commonly experiencing more stress as they need to complete multiple tasks at once. However, a different pattern of stress prevalence was recorded in this study in which medical students with part time job experienced lower prevalence of stress $(25.0 \%)$ compared to those without any part time job (33.5\%). It is commonly accepted having a close friend may reduce chance of developing or worsening stress. Previous study reported relationship with peers as a significant related factor to stress ${ }^{24}$. In this study, those with close friend experienced lower prevalence of stress $(32.1 \%)$ compared to those without close friend (48.4\%). Regarding engagement in love relationship, those who engaged in love relationship experienced lower prevalence of stress $(27.0 \%)$ compared to those who not engaged in love relationship (36.3\%). This finding was consistent with previous study which reported medical students who are not engaged in romantic relationship were found more stress compared those who involved ${ }^{24}$. Further association test reported love relationship as an insignificant factor although previous study reported it as a significant factor ${ }^{5}$.

Academic related stressors are generally related to the examination systems, assessment methods, grading methods, academic schedules and student activities related to academic events. Top academic related stressors were tests and examinations, large quantity of contents to be learned, lack of time to reviewed what has been learned, heavy workload and others ${ }^{17-20}$. The mean score of the academic related stressors was found to be at $2.117( \pm 0.758)$ which was the highest mean score among medical student stressors assessed by MSSQ. This finding have a similarity with previous study who reported academic related stressors were the major stressor among the medical students' stressors $^{1}$. Mean score of 2.117 was categorized as a high-level stressor by the MSSQ scoring manual which indicates that it causes a lot of stress and leads to emotional disturbance and daily activities are mildly compromised. Further association test reported ARS was statistically significant associated with development of stress among medical students $(p<0.001)$. This finding was consistent with previous similar studies ${ }^{5,17}$. Parametric test also reported statistically significant difference in mean score of
ARS between stressed and non-stressed medical student $(p<0.001)$. Therefore, it was clear to conclude ARS could be associated with the development of stress among medical student. The non-academic related stressors (IIRS, TLRS, SRS, DRS and GARS) were found to have mean scores ranging from 1.00 to 2.00. Mean score of 1.00 to 2.00 was categorized as moderate level stressor by the MSSQ scoring manual which indicate that it reasonably causes stress and can be managed well. All non-academic related stressors (IIRS, TLRS, SRS, DDRS and GARS) were found to be statistically significant associated with tendency of developing of stress among medical students $(p<0.001)$. This finding was consistent with the finding of previous similar study ${ }^{5}$. Further non-parametric test revealed statistically significant difference in mean score of non-academic related stressors (IIRS, TLRS, SRS, DRS and GARS) between stressed and nonstressed medical students. These findings were suggestive that to certain extent non-academic stressors (IIRS, TLRS, SRS, DDRS and GARS) were also contributed to the development of stress among medical students.

\section{Limitation of the study}

Self-answered questionnaire was the only tool used for data collection in which it may introduce some element of bias (over or under reporting) to the respondents. The questionnaire used was limited for measurement of the stress prevalence and identification of the related stress factors. Other related factors such as coping strategies and impact of stress were not able to be investigated. Therefore, the overall picture of the stress issue among medical students was not able to be illustrated in this study. As this was a cross-sectional study, the onset of stress problem among the medical students was not able to be determined. The cause-effect relationship was also unable to be established.

\section{CONCLUSION}

The findings of this study may indicate a need for continuous stress management programmes. The findings of this study can be used by the academic or faculty administrators for implementations and improvement of preventive measures, specifically for stress problem among medical student. A consideration needs to be given to the needs and difficulties of the medical students. It is hoped that these preventive measures can eliminate or at least minimize the unwanted consequences of stress on physical and mental health, social development, competency and academic performance among medical students. 


\section{RECOMMENDATIONS}

The academic administrator, academic staff and counsellor are recommended to come out with practicable modification, adjustment or control measures in order to reduce the negative consequence of stress. One of the recommended approaches is to conduct regular stress coping strategies course and workshop for medical students at the beginning (first year) and during their academic years (third year). This approach is expected to help them to cope with the ongoing stressors during their pre-clinical and clinical academic years. Another approach is to provide and maintain professional mental care services such as counselling and psychological support services to help the medical students to cope with the ongoing stress. Additional approach may involve practicable adjustment on certain medical curriculum to reduce the stressful learning environment in medicine programme.

As for future research, it is recommended for the researchers to apply face to face interview method as an instrument for data collection to reduce the possibility of under and over reporting bias among the respondents. Future researchers are also recommended to expand the spectrum of investigation so that a complete picture of stress problem among medical students can be illustrated in one single study. As this was a cross sectional study, the onset of problem and the cause-effect relationship was not able to be investigated. Therefore, it is recommended for future researchers to select longitudinal or cohort study as a choice of study design.

\section{Acknowledgement}

We would like to thank the Ethics Committee for the approval of this study, all respondents for their willingness to participate in this study and all individuals who had contributed to the completion of this study. This study is not funded by any institution.

\section{Conflict of interest}

None

\section{REFERENCES}

1. Siraj @ Ramli HH, Salam A, Roslan R, et al. Stress and its association with the academic performance of undergraduate fourth year medical students at Universiti Kebangsaan Malaysia. International Medical Journal Malaysia. 2014;13(1):19-24.
2. DSM-IV-TR. Diagnostic and statistical manual of mental disorders. American Psychiatric Association. 2000.

3. Abdulghani HM. Stress and depression among medical students: A cross sectional study at a medical college in Saudi Arabia. Pakistan Journal of Medical Sciences. 2008; 24(1), 12-17.

4. Malaysia Institute for Public Health. National Health and Morbidity Survey 2015 (NHMS 2015). Ministry of Health Malaysia.

5. Fuad MDF, Al-Zurfi BMN, AbdulQader MA, et al. Prevalence and Risk Factors of Stress, Anxiety and Depression among Medical Students of a Private Medical University in Malaysia. Education in Medical Journal, 2015.7(2).

6. Marjani A, Gharavi AM, Jahanshahi M, et al. Stress among medical students of Gorgan (South East of Caspian Sea), Iran. Kathmandu University Medical Journal, 2008; 6(3), 421425.

7. Bamuhair SS, Al Farhan Al, Althubaiti, et al. Sources of stress and coping strategies among undergraduate medical students enrolled in a problem-based learning curriculum. Journal of Biomedical Education, 2015; 1-8.

8. Elzubeir MA, Elzubeir KE and Magzoub ME. Stress and coping strategies among Arab medical students: towards a research agenda. Education for Health, 2010; 23(1), 355.

9. Attiya M, Al-Kamil EA and Sharif S. Stress and coping strategies among medical students in Basrah. The Medical Journal of Basrah University, 2007; 25(2), 27-32.

10. Eva EO, Islam MZ, Mosaddek ASM, et al. Prevalence of stress among medical students: a comparative study between public and private medical schools in Bangladesh. BMC research notes, 2015; 8(1), 327.

11. Moutinho ILD, Maddalena NDCP, Roland RK, et al. Depression, stress and anxiety in medical students: A cross-sectional comparison between students from different semesters. Revista da Associação Médica Brasileira, 2017; 63(1), 2128.

12. Saeed AA, Bahnassy AA, Al-Hamdan NA, et al. Perceived stress and associated factors among medical students. Journal of family \& community medicine, 2016; 23(3), 166. 
13. Salam A, Yousuf R, Bakar SMA, et al. Stress among medical students in Malaysia: A systematic review of literatures. Int Med J, 2013: 20(6), 649-655.

14. Al-Dubai SAR, Al-Naggar RA, Alshagga MA, et al. Stress and coping strategies of students in a medical faculty in Malaysia. The Malaysian journal of medical sciences: MJMS, 2011; 18(3), 57.

15. El-Masry R, Ghreiz SM, Helal RM, et al. Perceived stress and burnout among medical students during the clinical period of their education. Ibnosina J Med Biomed Sci, 2013; 5(4), 179-88.

16. Al Sunni A, and Latif R. Perceived stress among medical students in preclinical years: A Saudi Arabian perspective. Saudi Journal for Health Sciences; 2014, 3(3), 155.

17. Yusoff MSB, Rahim AFA and Yaacob MJ. Prevalence and sources of stress among Universiti Sains Malaysia medical students. The Malaysian journal of medical sciences: MJMS, 2010; 17(1), 30.

18. Yusoff MSB, Rahim, AFA and Yaacob MJ. The development and validity of the Medical Student Stressor Questionnaire (MSSQ). ASEAN Journal of Psychiatry, 2010; 11(1), 231-5.

19. Yusoff MSB, Rahim AFA and Yaacob MJ. The prevalence of final year medical students with depressive symptoms and its contributing factors. International Medical Journal, 2011; 18(4), 305-309.

20. Yusoff MSB, Yee LY, Wei LH, et al. A study on stress, stressors and coping strategies among Malaysian medical students. International Journal of Students' Research, 2011; 1(2).
21. Dass T., and Foundation P. Depression Anxiety Stress Scales (DASS). 2005.

22. Mohd Sidik S, Rampal L and Kaneson N. Prevalence of emotional disorders among medical students in a Malaysian university. Asia Pacific Family Medicine, 2003; 2(4), 213-217.

23. Ab J and Hassim IN. Stress and Coping Strategies Among Medical Students in National University of Malaysia, Malaysia University of Sabah and Universiti Kuala Lumpur Royal College of Medicine Perak. Journal of Community Health. 2009.

24. Zaid ZA, Chan SC and Ho JJ. Emotional disorders among medical students in a Malaysian private medical school. Singapore medical journal, 2007; 48(10), 895. 